\title{
Blood Type Diets (BTD) and Aging: An Overview
}

\section{Marcello Menapace*}

M\&MS Consulting Ltd., Borehamwood, Hertfordshire, UK

*Corresponding author: Dr. Marcello Menapace, M\&MS Consulting Ltd., Borehamwood, Hertfordshire, UK, Tel: +44-7423466123; E-mail: dr.m.menapace@gmail.com

Received date: December 14, 2018; Accepted date: January 24, 2019; Published date: January 31, 2019

Copyright: (c) 2019 Menapace M. This is an open-access article distributed under the terms of the Creative Commons Attribution License, which permits unrestricted use, distribution, and reproduction in any medium, provided the original author and source are credited.

\begin{abstract}
It has recently been proposed that glycans, being the third alphabet of life, interact intricately with endogenous biomolecules to modulate tolerance, immune and inflammatory responses. Specifically, food glycans could impact health and be a source of inflammation and age-related diseases. These special carbohydrates are present as glycoconjugates (glycoproteins or glycolipids) in and on the surface of all the cells (glycocalyx) of all organisms or are found in free form in biological fluids. Recent advances in glycobiology and glycochemistry have shown how glycans bind with naturally present human proteins (lectins), through protein-carbohydrate interactions (or $\mathrm{PCl}$ ), but also how oligosaccharides can interact with other glycans, present throughout the human body (through carbohydrate-carbohydrate interactions, or $\mathrm{CCl}$ ). Oligosaccharides present in food sources, which go beyond the definition of normal fibers, once ingested are then either absorbed in the bloodstream, where they are recognized by the immune system, or interact with the surface of $\mathrm{Gl}$ epithelial cells, thus generating appropriate biochemical cascades that induce a tolerance or immune/inflammatory response. Because the $A B O$ epitopes have been encountered on all human cells, not just erythrocytes and based on the different biotypology $(A, A B$, B, and $O)$ impose morphic changes in the distribution of the glycans on the glycocalyx (lipid rafts and clustered saccharide patches), their $\mathrm{CCl}$ with food and microbe glycans will be different, thus, eliciting contrasting responses. This can explain the epidemiological data for blood type diets (BTD). Through continuous consumption of the wrong types of glycans, processes of chronic inflammation could be initiated and progress to accelerated aging. Four basic modes of action have been identified showing how glycans can trigger inflamm-aging. Since glycobiology is a young science, further studies with newer technologies are warranted for advancement in this field.
\end{abstract}

Keywords: Glycan; Aging; Inflammation; ABO antigens; Glycotopes; Food antigens

\section{Introduction}

It is a well-established fact, now, that complex carbohydrates are ubiquitous in nature [1]. Carbohydrates are also called glycans to underline the functional diversity and complexity of their structural composition [2]. For over a century, the areas of nucleic acids, proteins and lipids have captured the attention of investigators worldwide [3]. On the other hand, carbohydrates, due to their inherent higher complexity and non-genome origin, have only more recently received increased attention through the expanding field of glycobiology [4-6].

Because of their unique chemical properties, glycans have unsurpassed structural variability, and enormous changeability beyond the simple sequence, as for proteins or nucleic acids [7]. The presence of an anomeric carbon atom, the possibility of linkage formation involving different acceptor sites and the ring size with frequent occurrence of branching and site-specific modifications allows glycans to display unique properties $[8,9]$. Hence, it can be stated that the proteosome and the nucleosome are no match for the glycome, as the coding capacity of the oligosaccharide language is simply orders of magnitude higher [10]. Only recently these ubiquitous molecules have been considered in nutrition and have been associated with many factors linking food components to health or disease [11]. Given the recent advances in glycobiology and glycochemistry, it is about time that nutritional sciences incorporate such tiny sweet molecules as fundamental constituents of the nutritional environment [12].

\section{Literature Review}

Although blood type diets (BTD) have been around for a couple of decades, it has slowly gained momentum and widespread attention [13]. Since it was launched in 1996, several physicians have experimented (through empirical observations) with the diet and have found strong evidence in favor [14-17]. Nevertheless, it is reported that there's a lack of evidence supporting the BTD hypothesis [18]. To date, only one serious mechanistic explanation, apart from the lectin hypothesis, has been put forward for BTD and involves the intervention of glycans [11]. Their presence in food and their particular biochemistry make them exceptionally prone to interact with human biomolecules and elicit and modulate immune and/or inflammatory responses [11,19-22]. Ultimately, these processes of inflammation and immune tolerance could be regarded as possible underlying initiators of aging and age-related diseases [23,24]. Inflamm-aging (aging from inflammation) is deemed the long-term result of chronic stimulation of the innate immune system [25]. In order to understand how glycans molecular biology and biochemistry influence the process of aging and disease, a cursory overview of their occurrence, antigenicity and immune signaling potential is required.

\section{Glycocalyx and signaling mechanism}

The cell surface is literally coated with carbohydrates in the form of glycoproteins, with oligosaccharides (sugar residues), proteoglycans, with polysaccharides, and glycolipids (as glycoconjugates) [26,27]. This layer is called the glycocalyx and is responsible for a vast number of biological functions [28-30]. Some of the most important roles include: 
Page 2 of 9

ion exchange, receptors, cellular recognition, cell adhesion and development, regulation of myriad receptor: ligand interactions at the cell surface, to protein folding and activity [31-33]. Others are more related to immune regulation, such as modulation of signaling, or direct immune regulation self or non-self-recognition and homeostasis [34-37].

Moreover, the outer layer glycocalyx interacts with the extracellular matrix (ECM). This can occur due to the closeness between the two layers [38]. The ECM is composed primarily of glycosaminoglycans (GAGs, such as heparan sulfates, chondroitin sulfates and hyaluronan) and proteoglycans (PG, of two main families, syndecans and glypicans) [39]. For further reference, authoritative and comprehensive reviews of the biological roles of glycans and their impact on the immune system are available $[12,40,41]$. It is undeniable that glycan-binding proteins (GBPs), or lectins, play a pivotal role in many different aspects of the physiology, including the immune defence [42].

There is evidence for a myriad of roles for lectin-carbohydrate interactions, including intracellular signaling pathways that regulate the immune response $[43,44]$, and modulating roles in many different biological processes $[42,45]$. This suggests that lectins and sugars mediate their effects through non-redundant pathways [46]. Several of such GBPs function as pattern recognition receptors (PRRs) [43]. PRRs are receptors that recognize a wide variety of external pathogenassociated molecular patterns (PAMPs) [47]. PRR also react to endogenous molecules like damage associated molecular patterns (DAMPs), closely linked to inflammation [48]. Activation of membrane-bound or intracellular PRRs by special exogenous and internal determinants initiate signaling events linked to innate immune responses [49]. C-type lectin (CTL) receptors (CLRs) are among the most efficient PRRs and interact with glycan structures on microorganisms leading to adaptative immune response [50].

Another phenomenon known as 'lipid raft', has a central role in this signaling scenario [49,51]. Lipid rafts are essentially the compartmentalization in time and space of lipid and protein cargo on the plasma membrane of cells [52]. The cell membrane is starred also with sphingolipids and glycosphingolipids (GSL) forming special microdomains [53]. Both glycolipids, glycoproteins and GPI proteins can reorganize (or self-associate) themselves spatially on the cell surface in these microdomains [54]. The reorganization in lipid rafts occurs through protein-carbohydrate interactions (PCI) or carbohydrate-carbohydrate interactions (CCI) to form glycolipidenriched membrane microdomains of submicron length $[31,55,56]$. Many proteins with raft affinity, all heavily glycosylated have the ability to laterally segregate in fluctuating nanoscale assemblies (membrane sub compartmentalization) of sphingolipid, cholesterol, and proteins [57,58]. Multivalent binding between carbohydrates and proteins increases the avidity of cell signaling, molecular recognition and inflammations [59].

Lipid rafts, consisting of clusters of structural proteins, enzymes, and signaling receptors, regulate several biological functions, especially signaling events [60]. This has been confirmed by other studies suggesting that such rafts could play an important role in many cellular processes including membrane trafficking, cytoskeletal organization, and pathogen entry [61-63]. Moreover, galectin-4 or -8 , can bind to and cross-link multivalent glycoproteins and glycolipids of lipid rafts, leading to formation of micro domains and lattices that initiate signal specific pathways $[64,65]$. The formation of these lipid raft assemblies are known to be responsible for initiating many signal transduction pathways, including those for immune cell activation [36]. Finally, the (epithelial) glycocalyx has emerged as an important participant in modulating inflammation, infection and allergic processes [39].

\section{Food glycans and antigens}

Food antigens: Dietary antigens or allergens (substances present in food) are known to elicit immunologic reactions generally defined under the category of food hypersensitivity (FHS) [66]. Among the many types of reactions to food components, dietary cross-reactive antigen epitopes have often been associated with food allergies and food intolerances [67]. In literature, epitopes are implicitly assumed to exclusively consist of amino acids, but glycan epitopes and classical haptens are important IgE-binding epitopes [68].

A hypothesis that the carbohydrate structures are another potential source of immunological cross-reaction between different plant allergens was proposed in the 1980s [69,70]. Since then, many food glycans (as xeno-glycans) were isolated, identified and structurally characterised [71,72], called cross-reactive carbohydrate determinants (CCD) [73]. CCDs generally have vast structural variability consisting of oligomannosidic hybrid or complex type structures [74,75]. These CCDs have been shown to have immunomodulatory weak allergic and/or non-allergenic immunogenic properties, either as free (unlinked) glycans or on (glyco)protein allergens [70,76-78]. Some may also cause false-positive allergologic tests [75]. Identifying the number, structure, and function of glycans in cellular biology is a truly daunting task [28]. Glycans are present on a myriad of nuclear and cytoplasmic proteins [29]. Furthermore, they are endowed with diverse and complicated structures, typical of oligosaccharides (chains of monosaccharides between 3 and 20 sugar units in length) [76]. Dissimilarly to proteins or nucleic acids, which are linear, the glycosidic linkage in oligosaccharides have multiple attach points on the sugar ring, thus allowing both linear and branched structures (called antennae) [7]. The majority of bi-, tri-, and tetra-antennary glycans found in nature have diverse sugar residues linked to the terminal $\mathrm{N}$-acetylglucosamine (GlcNAc) giving rise to distinct glycan determinants [79].

The main carbohydrates included in human diet are polysaccharides in the form of starches, with variable chain length, monosaccharides and disaccharides (sucrose and lactose) [80]. There are other nonstarchy carbohydrates, normally called dietary fibres, that do not possess either $\alpha$ or $\alpha$ glycosidic bonds and are hence not hydolysable by the human digestive enzymes $[1,4,6,81]$. Indeed, non-digestible plant fibers can be divided into insoluble (cellulose, hemicellulose and lignin) and soluble (gums and pectins) fibers [82]. These can be metabolized only by the microbiota in the cecum and colon [83]. Further types of fibre include prebiotics, such as inulin and oligofructose (also called fructooligosaccharides (FOS)) galactooligosaccharides (GOS), and the human milk oligosaccharides (HMO) [84,85]. These special carbohydrates, too, can manifest properties not unlike those displayed by the food glycans previously discussed [11].

ABO epitopes: Most interestingly, many food antigens seem to be carbohydrate moieties similar to the histo-blood group antigens (HBGA). Human HBGA are glycan structures and carbohydrate epitopes present on glycoproteins and glycolipids of human cells [86]. HBGAs are classified into four groups (type 1, 2, 3 and 4), depending on the binding position ( $\alpha$ or $\beta$ ) of sequential carbohydrate moieties [87]. Several studies $[72,88,89]$ have found HBGA like glycans on glycoproteins and glycolipids in diverse food sources such as oysters, clams, fruits and vegetables. Recently researchers have also found 
HBGA-like saccharides on the cell wall of lettuce [90]. ABO group determinants were first discovered in the blood. The ABO blood group is the most important blood group system in transfusion and transplantation medicine [91]. The ABO blood system consists of four blood types (A, B, AB and $\mathrm{O}$ ) [92]. Three variant alleles (A, B, and $\mathrm{O}$ ) of a single gene on chromosome $9 \mathrm{q} 34$, the $\mathrm{ABO}$ gene, determine a person's blood type by encoding two active glycosyltransferases (A and B) with different substrate specificities [93]. The $\mathrm{H}$ or $\mathrm{O}$ antigen encodes an inactive glycosyltransferase [92].

The ABO blood group is intimately linked to another blood group of carbohydrate origin: the Lewis blood type [94]. Serologically, Lewis status is defined by the expression of two main antigens: Lea and Leb antigens [95]. Four possible Lewis phenotypes, although only three are commonly encountered in adults : $\mathrm{Le}(\mathrm{a}+\mathrm{b}-)$, Le (a-b+), and $\mathrm{Le}(\mathrm{a}-\mathrm{b}-)$. Lewis glycans are also important in the distinction of humans into two categories based on secretor and non-secretor status [94]. The HBGA and $\mathrm{ABO}$ moieties have a wide tissue distribution in human cells [96]. In addition to their expression on the surface of red blood cells, the $\mathrm{ABO}$ and Lewis antigens are highly expressed on the surface of epithelial cells of the gastrointestinal (GI), bronchopulmonary, and urogenital tracts [88]. The expression of $\mathrm{ABO}$ antigens is also found on lymphocytes, platelets, endothelial cells and most epithelial cells $[97,98]$. Moreover, they are found in the saliva in several other biological tissues, in human milk (also as free oligosaccharides), and in general on the mucosal epithelium of the GI tract [76,89,99-103].

The other two carbohydrate antigen systems closely linked to both $\mathrm{ABH}$ and Lewis are $\mathrm{Li}$ and the globo series ( $\mathrm{P}$ antigens), often found on glycolipids [41]. ABH antigens on red blood cells can modulate cellular interactions without being a direct ligand themselves, but by stabilizing other carbohydrates on the fluid cell surface in clusters (called "clustered saccharide patches") [104]. Depending on the ABO blood type, the $\mathrm{ABH}$ antigens could interact through CCI or PCI with other glycans making them more (or less) accessible to relevant GBPs. The clustering of these closely spaced oligosaccharides, forced into an uncommon conformation, favors a high-affinity recognition needed for correct GBP binding to the glycans [105]. The stabilizing effect of these clusters demonstrated that the HBGAs can effectively modulate CCI involving other glycans ( $\alpha 2-3$-linked Sias and $\alpha 2-6$-linked Sias), without being directly involved or being the primary target of GBPs [106]. Hence, glycan diversity together with special spatial conformation (unique clustered saccharide patches facilitated by $\mathrm{ABH}$ antigens) can be differentially recognized by GBPs, showing binding specificity [107].

\section{Glycan Reactions}

Lectins: Glycans, as highly structurally variable biomolecules can be selectively and with high affinity bound to special proteins, called lectins, present ubiquitously and abundantly in all phyla $[7,108]$. Although lectins (GBPs) recognize glycans with high affinity, nonetheless glycans display also multivalency as a feature by which their density and spatial organization can modulate the binding [109]. This effect, known as glycoside cluster effect, provides a mechanism for enhancing the overall affinity and selectivity of glycan recognition by lectin [110].

Several GBP (or carbohydrate-binding proteins, CBP, namely lectins) are present in nature and have been recovered in diverse food sources, being widely distributed among plants and animals [111]. Lectins are known to be anti-nutritional factors and to cause intestinal disorders [112]. The original mechanism to explain the workings of
BTD was based on the presence of lectins in foods [113]. These CBPs are generally very resistant to heat and digestion, and have been recovered in active form throughout the colon and in the faeces $[114,115]$. CBPs are so selective that they are capable of recognizing just one to four monosaccharides organized in a special arrangement, called motif [116]. Lectins also showed polyvalent behaviour displaying the ability to bind to various glycoforms [117].

The binding of lectins is inhibited by most high-density polyvalent oligosaccharides-containing glycoproteins and their cryptoforms, masked by similar sugar residues such as blood group determinants or sialic acids [117]. Dietary lectins act as PRRs which bind to specific epitopes on surface glycoproteins (or glycolipids) on the glycocalyx of several cell types [118]. Quite a few hundred plant lectins have been identified so far, with various classification systems being proposed [119]. Some toxic effect of lectins can be attributed to the partial resistance to proteolysis in vivo [113]. But this explanation may not be only valid for local (GI) effects, but also for systemic effects as lectins can induce IgE-mediated and IgG-mediated reactions [112]. Although some lectins are known to resist degradation in the alimentary canal and crossover to the circulatory system, they are normally not expected, as proteins, to be absorbed as is [120]. Anyhow, there is a lack of depth of the mechanistic complexity needed to entertain the many biochemical and biological phenomena (inflammatory and immunologic reaction) that result from food consumption.

Glycans: An innovative mechanism is required as both central and supplementary to the already existing one. Food glycans (like all glycans) have special biochemical properties that allow them to manifest molecular mimicry (structurally similar though with chemically different features) with HBGA [108]. Molecular mimicry is the phenomenon in which glycans with various structures and different moieties can appear to be identical or nearly identical to those found on their host cell surfaces [12]. The mechanism considers molecular mimicry as a fundamental property of glycans. Nevertheless, the following mechanism for generation of immune and inflammatory responses is an incomplete summary of all the possible interactions of food glycans with the human biochemical network. Four principal modes of action (MOA) have been identified.

The starting point is the ingestion of oligosaccharides with food. The oligomeric sugar moieties present unbound or bound on the glycoconjugates of the various food items are not degraded during digestion $[69,84]$. Once the undigested carbohydrates arrive intact at the level of the intestinal mucosae, they can either

1) Interact with the human lectins, such as galectin- 4 or -8 , present in the GI tract $[121,122]$, or

2) React with glycans of glycoconjugates of various types on the cell membranes of the enterocytes [117], or

3) Be processed differentially by the gut microflora resulting in (a) Production of useful short-chain fatty acids (SCFA), which have beneficial effects [123]. (b) Variation of the composition of the gut microbiota (positively or negatively], which will consequently influence inflammation [124].

4) Be absorbed into the internal milieu by diffusion or pinocytosis where they (a) Are presented to the APCs (antigen-presenting cells), such as dendritic cells, which will present the glycan for the generation of specific anti-glycan antibodies (AGA) [34,125]. (b) Interact with the complement proteins through the lectin pathway. 
Either one of these distinct MOA (1,2,3 and 4) will elicit or modulate an immune, tolerance or inflammatory response $[35,44,126]$. It is also likely that all of these MOA can occur at the same time and for each glycan (depending on the concentration and food kinetics).

Moreover, all of these MOA are modulated by HBGAs, as the principal glycoform ubiquitously present in humans. The HBGAs can interfere in the binding of endogenous lectins to antigens, so that $\mathrm{ABO}$ blood group can differentiate individuals and their reactivity towards any glycan or lectin $[104,106]$. The presence of a particular blood group glycan can modify the glycan reactivity of cell surface glycoconjugates towards human GBPs (PRRs) or towards GBPs of animal, vegetable (food) or microbial origin [107]. Therefore, the HBGA epitopes of glycans on glycoproteins/glycolipids generate specific recognition epitopes [106]. The formation of multivalent interactions between glycoproteins/glycolipids and clustered surface glycans is favored in lipid rafts [36]. This contributes to special plasma membrane architecture and peculiar cellular properties, typical of each ABO phenotype [127].

These ABO-mediated changes in membrane topology can explain the several pathophysiologic differences between various blood groups [128]. ABO blood type has been linked to a number of diseases, including cancer and musculoskeletal diseases [92]. For example, blood group A was confirmed by several studies to be associated with elevated risk of gastric cancer, while blood group $\mathrm{O}$ with lower risk of pancreatic cancer [129]. These differences may be due to the presence of different ABO glycans. As a consequence, specific PCI or CCI with $\mathrm{ABO}$ glycotopes are primarily responsible for mechanisms of self or non-self-discrimination of our innate and adaptive immune system [130]. Xeno-determinants can finally be recognised as self or non-selfdepending fundamentally on the resemblance to $\mathrm{ABO}$ glycoforms.

The MOA 1 and 2, involving the interaction between food glycans and human lectins and glycoconjugates, can occur also on other cells once they are passing the intestinal barrier. As glycoconjugates are abundant in food items, the density and concentration of these glycans reaches a considerable amount. There is increasing evidence that even low concentrations of these glycans are enough to reach signaling threshold and initiate numerous biological processes [29].

MOA 1: The undigested oligoglycans (for example HBGA-like moieties found in food, xenoantigens) form high affinity PCI with soluble (galectins) or membrane-bound human lectins (PRRs) $[90,131]$. The interaction will impose morphodynamic changes to the transmembrane proteins in the lipid rafts and evoke a biochemical response [132]. Food glycans can interact with mono-, di- or polyvalent human lectins, such as ABO specific GBPs, through PCI, which may be multivalent to further increase the affinity by several orders of magnitude or CCI $[7,114,133]$. Galectin- 4 or -8 , may bind to and cross-link multivalent glycoproteins and glycolipids on the cell surface in appropriately formed lipid rafts, leading to formation of microdomains and lattices that initiate signal specific pathways [64,134]. High affinity ligands to selectins, antibodies, and other types of GBPs $[105,135,136]$, are favored by the presence uncommon conformations of glycans in HBGA enhanced clustered saccharide patches. Such GBPs (siglecs and galectins) play critical roles in diverse cellular functions such as cell adhesion, signal transduction and immune response [137]. Galectins for example have been established as important regulators of innate and cell-mediated immune homeostasis, inflammation, malignancy, and autoimmune disease [138].
MOA 2: After the first putative multivalent CCI was hypothesized, several studies demonstrated the existence, ubiquity, polyvalent selfinteraction/recognition and strength through multimerization or glycoside cluster effect of such interactions [31,61,101,134,139-148]. In this MOA, the binding occurs with a high-affinity PCI and with low affinity CCI [149]. Once PCI or CCI between glycans and surface receptors are established, the formation of special cross-linking between GBPs and glycoproteins, called lattices, may be favored or impeded depending on the particular functional and spatial conformation of the membrane lipid rafts [60].

Lipid rafts are glycolipid enriched domains that function as a signaling compartment in the plasma membrane [63]. Several glycoproteins in these lipid micro domains display clear signal modulated interaction (glycosylation dependent signal transduction) by the glycans of glycolipids, via ultralow affinity but multivalent CCI $[31,53,61,150]$. The nanoscale heterogeneity of the lipid rafts is functionalized to larger levels by lipid- and/or protein-mediated activation events (e.g., multivalent ligand binding of glycans between glycolipids and glycoproteins) [33]. The discrimination between self and nonself (on the basis of glycan determinants) can be accomplished by AGAs and GBPs of the innate immune system [79]. But this depends on what is recognized as self therefore essentially on what resembles the ubiquitous HBGA [11].

MOA 3: This MOA has been amply documented and reviewed elsewhere and will be just briskly discussed $[11,124]$. The importance of the intestinal microflora in health cannot be overstated [151]. As it is known that dietary fibers allows for a more diversified gut microbiota which is beneficial for the host, glycans are hardly ever deemed important or spelled out. Of course, they could not have been considered as they were practically unknown to the nutritional community [152].

MOA 3a: Briefly, the structural and chemical variability of glycans is so great that a vast gene pool is required to encode for enzymes capable of degrading the diverse glycans. SFCAs have been linked to a vast array of beneficial effects. An association between cellular metabolism (a major energy source for intestinal cells), SCFAs, and transcriptional regulation (with consequential immune modulation) has recently been established [153].

MOA 3b: Microbes are known to adhere to biological surfaces, including the surface of human cells, through PCI and CCI [154]. Since the main glycan structure in the human body is the HBGA glycoform, microbes have high affinity to each individual's $A B O$ glycophenotype. Indeed, recent findings strongly suggest HBGA are an important factor modulating the intestinal microbial composition $[11,94]$. There is hence an alignment between the host ABO phenotype and the HBGA expressing bacteria (microbiome) [155]. Actually, human gut microbiota degrades both dietary and host glycans with the use of carbohydrate active enzymes (CAZymes) [156]. Those that are better suited to attach to a particular $\mathrm{ABO}$ phenotype will have the advantage to better feed on host glycans for carbon and energy [94,157].

Diet (in the form of the types of glycans present in foods) shapes gut microbes and affects their composition and function, impacting hostmicrobe interactions $[11,158]$. The ingestion of the wrong glycans may favour pathogens, or incorrectly $\mathrm{ABO}$-aligned microorganisms, thus resulting in dysbiosis (with deleterious effects) [159]. Dysbiosis will negatively affect health. 
Page 5 of 9

MOA 4a: Although there is a myriad of AGA present in human serum, their generation and function are not well understood [125]. Normally, healthy humans harbor sets of AGA to blood group-, xeno(heterophil), and infection-related glycotopes [160]. If, after presentation by the appropriate APC, an AGA recognizes a presented food glycan to be molecularly similar to a non-self (xeno) antigen, the AGA will react and elicit an immune response. CCDs have been observed between environmental and food allergens through high levels of IgE AGA [161]. For example, there are circulating AGA in healthy humans against $\mathrm{N}$-glycolylneuraminic acid (Neu5Gc) and galactose alpha-1,3-galactose ( $\alpha$-gal), glycans present in dairy products and red meats [162].

MOA 4b: A further intriguing possibility not mentioned before is the interaction with the complement proteins (thus, directly with the innate immune system). The complement is a complex network of plasma proteins, present in the blood, but also in other body fluids, and is an integral part of the innate immune system [163]. The lectin pathway is one of the three modes of activation of the complement and proceeds through pattern recognition of glycans by serine protease lectins [164]. The lectin pathway uses mannose-binding lectin (MBL), ficolins (ficolin-1, -2 and -3) as well as collectin-10 and -11 (all lectins), as initiator molecules to recognize glycan DAMPs and PAMPs [165]. Fucolins and collectins act as PRRs forming complexes with MBLassociated serine proteases (MASPs) to initiate complement activation and display different and diverse specificities in their binding to ligand (glycans) [166]. Given that diverse glycan can exhibit molecular mimicry to resemble host glycans, it is chemically feasible that these can also resemble PAMPs or DAMPs thus triggering complement initiation. Unwarranted activation of complement system and tissue deposition of complement activation products can lead to systemic inflammation [164]. Since inflammation is the hallmark of aging, continuous absorption of such deleterious glycans can maintain high levels of inflammation [167].

All MOAs: Notwithstanding any of the four MOA, the result is the same: food ingredients can interact with the human GI mucosae and/or cross the intestine barrier into the blood stream. Specifically, glycans can be absorbed by cells and circulate in the body [9]. Several studies demonstrated AGA are found in the blood of non-allergic donors, confirming food glycans can cross the barrier [168]. From here, how the immune system perceives these glycans, self or non-self, dictates how it will react: immune/inflammatory or tolerance response. Notably, an association between the increased inflammatory and immune responses and aging has already been made [169]. While over nutrition is known to drive chronic metabolic inflammation, also dysbiosis with the increased release of inflammatory products contribute to inflamm-aging [25]. Ultimately, chronic low-grade inflammation and immune response lead to accelerated aging processes [170]. This glycan interaction explanation for immune and inflammatory processes is not meant to substitute the previously confirmed ABO-food interaction (food lectins binding to human glycoconjugates) but to be supplementary to it.

\section{Discussion and Conclusion}

The BTD was first proposed by PJ D'Adamo in 1996 [171]. The scientific community has been healthily skeptical towards these claims for lack of a controlled, randomized trial, but also for lack of a coherent mechanism $[15,172,173]$. What has been concisely and incompletely expounded is a complex network of interactions (between endogenous and xeno glycans, microbiota and human GBPs), that influence health and may trigger immune and inflammatory processes [11]. The actions of GBPs have been well studied and verified in the context of carbohydrate recognition for or a wide range of biological activities, This overview takes into account the number, structure, and function of glycans in cellular biology in sum it encompasses the multifaceted reality of glycan chemistry and the glycome $[28,174,175]$.

Nearly every disease process (mostly involving disordered inflammation and immunity), that affects humans and other animals, pertain to glycans [29]. Science is homing into the definition of the exact mechanism for several food hypersensitivities and, slowly, it will be possible to isolate the specific food glycan structures responsible for inflammatory and immunogenic responses $[43,44]$. It has been shown that food glycans can cause inflammation or immune-mediated responses based on $\mathrm{ABO}$ typology, as recommended by the BTD [34,59]. Given the multifaceted biochemical activities of the ubiquitous glycans, their chemistry and biology, following BTD may help reduce the sources of inflammation $[11,176]$. As a consequence of continuous ingestion of non $\mathrm{ABO}$ aligned glycans, chronic inflammation could develop by any of the mentioned MOA and persist leading to accelerated aging [169].

Because of the various specificities between lectins and the myriad different glycans (interactions between proteins and glycolipid complexes glycolipids and glycolipids, and glycolipids and other carbohydrate complexes), it is not astonishing that the role of food glycans has been missed until now [135,144]. The dearth of information concerning glycans and their presence in food is due essentially to the lack of access to glycans, the poor throughput of traditional assays and the challenges of profiling of AGA [125]. Studies in this field are poised to accelerate greatly due to the availability of high throughput and high-content technologies such as the multiplex glycan bead array (MGBA) [137]. As we progress through technical advances (biophysical approaches), we will be able to create new methods to distinguish subtle differences of microdomains and thus find new PCI and CCI between glycosyl epitopes on glycoproteins and glycolipids [61].

\section{Acknowledgements}

M\&Ms Consulting Ltd has provided necessary equipment for the writing of the article.

\section{Competing Interests}

The authors declare no competing interests.

\section{References}

1. Woods RJ (2018) Predicting the structures of glycans, glycoproteins, and their complexes. Chemical Reviews 118: 8005-8024.

2. Yamaguchi Y (2015) In: Taniguchi N, Endo T, Hart GW, Seeberger PH, Wong CH (eds.) Glycoscience: Biology and medicine (1 $1^{\text {st }}$ edn.) Springer Japan, Tokyo, Japan.

3. Ghazarian H, Idoni B, Oppenheimer SB (2011) A glycobiology review: Carbohydrates, lectins and implications in cancer therapeutics. Acta Histoche 113: 236-247.

4. Chaliha C, Rugen MD, Field RA, Kalita E (2018) Glycans as modulators of plant defence against filamentous pathogens. Front Plant Sci 9: 928.

5. Gill SK (2016) Exploring the role of glycosylation in vascular biology, immunology, and stem cell biology. 
Page 6 of 9

6. Pysmenetska I, Butters T (2016) Serum glycomarkers of endoplasmic reticulum stress and lysosomal-endosomal functional disturbances in cardiovascular diseases. Ukr Biochem J 89: 59-70.

7. André S, Kaltner H, Manning JC, Murphy PV, Gabius HJ (2015) Lectins: Getting familiar with translators of the sugar code. Molecules 20: 1788-1823.

8. Battistel MD, Azurmendi HF, Yu B, Freedberg DI (2014) NMR of glycans: Shedding new light on old problems. Prog Nucl Magn Reson Spectrosc 79: 48-68.

9. Samraj AN, Bertrand KA, Luben R, Khedri Z, Yu H, et al. (2018) Polyclonal human antibodies against glycans bearing red meat-derived non-human sialic acid N-glycolylneuraminic acid are stable, reproducible, complex and vary between individuals: Total antibody levels are associated with colorectal cancer risk. PloS one 13: e0197464.

10. Dean L (2005) Blood groups and red cell antigens: National Center for Biotechnology Information, Bethesda, USA.

11. Menapace M (2018) Recent advances in nutritional sciences: An overview of glycans and miRNAs. J Nutr Food Sci 8: 734.

12. Varki A (2017) In: Cummings RD, Esko JD (eds.) Essentials of glycobiology. (2nd edn) Cold Spring Harbor Laboratory Press, Cold Spring Harbor, New York, USA.

13. Wang J, García-Bailo B, Nielsen DE, El-Sohemy A (2014) ABO genotype, 'blood-type'diet and cardiometabolic risk factors. PloS One 9: e84749.

14. Poleszynski DV (2001) Blood type diet tens vitenskapelige grunnlag. Tidsskr Nor Lægeforen Nr 121: 1838-1839.

15. Meltzer HM, Haugen M, Haavardsholm KC, Hagen KB, Heier HE, et al. (2002) Blodtypedietten-visjonaer vitenskap eller tull? Tidsskr Nor Lægeforen Nr 122: 1402-1405.

16. Mozzi P (2012) La dieta del dottor Mozzi. (2nd edn) Casa Editrice Coop Mogliazze Piacenza, Italy, p: 144.

17. Power L (2007) Biotype diets system ${ }^{\circ}$ : Blood types and food allergies. J Nutr Environ Med 16: 125-135.

18. Wang LL, Wang Q, Hong Y, Ojo O, Jiang Q, et al. (2018) The effect of lowcarbohydrate diet on glycemic control in patients with type 2 diabetes mellitus. Nutrients 10: E661.

19. Dube DH, Bertozzi CR (2005) Glycans in cancer and inflammationpotential for therapeutics and diagnostics. Nat Rev Drug Discov 4: 477.

20. Pomin VH (2015) Sulfated glycans in inflammation. Eur J Med Chem 92: 353-369.

21. Rabinovich GA, Toscano MA (2009) Turning'sweet'on immunity: Galectin-glycan interactions in immune tolerance and inflammation. Nat Rev Immunol 9: 338.

22. Raman R, Raguram S, Venkataraman G, Paulson JC, Sasisekharan R (2005) Glycomics: An integrated systems approach to structure-function relationships of glycans. Nat Methods 2: 817.

23. Chung HY, Cesari M, Anton S, Marzetti E, Giovannini S, et al. (2009) Molecular inflammation: Underpinnings of aging and age-related diseases. Aging Res Rev 8: 18-30.

24. Agrawal A, Agrawal S, Tay J, Gupta S (2008) Biology of dendritic cells in aging. J Clin Immunol 28: 14-20.

25. Franceschi C, Garagnani P, Parini P, Giuliani C, Santoro A (2018) Inflamm-aging: A new immune-metabolic viewpoint for age-related diseases. Nat Rev Endocrinol p: 1.

26. Alberts B, Bray D, Hopkin K, Johnson A, Lewis J, et al. (2015) Essential cell biology: Garland Science, Taylor \& Francis Group, New York, USA.

27. Li D, Breiman A, Le Pendu J, Uyttendaele M (2015) Binding to histoblood group antigen-expressing bacteria protects human norovirus from acute heat stress. Front Microbiol 6: 659 .

28. Hart GW, Copeland RJ (2010) Glycomics hits the big time. Cell 143: 672-676.

29. Varki A (2017) Biological roles of glycans. Glycobiol 27: 3-49.

30. Zhang Y, Zeng Y (2017) A scientometric review of glycocalyx research (2007-2016). J Biomed 2: 124-133
31. Lai CH, Hütter J, Hsu CW, Tanaka H, Varela-Aramburu S, et al. (2015) Analysis of carbohydrate-carbohydrate interactions using sugarfunctionalized silicon nanoparticles for cell imaging. Nano lett 16: 807-811.

32. Egberts HJA, Koninkx J, Van Dijk JE, Mouwen J (1984) Biological and pathobiological aspects of the glycocalyx of the small intestinal epithelium: A review. Vet Quart 6: 186-199.

33. Van Slambrouck S, Groux-Degroote S, Krzewinski-Recchi MA, Cazet A, Delannoy P, et al. (2014) Carbohydrate-to-carbohydrate interactions between $\alpha 2$, 3-linked sialic acids on $\alpha 2$ integrin subunits and asialo-GM1 underlie the bone metastatic behaviour of LNCAP-derivative C4-2B prostate cancer cells. Biosci Rep 34: e00138.

34. Crespo HJ, Lau JT, Videira PA (2013) Dendritic cells: A spot on sialic acid. Front Immunol 4: 491.

35. Coombe DR, Parish CR (2015) Carbohydrates: The yet to be tasted sweet spot of immunity. Front Immunol 6: 314 .

36. Vasta GR, Ahmed H, Nita-Lazar M, Banerjee A, Pasek M, et al. (2012) Galectins as self/non-self-recognition receptors in innate and adaptive immunity: An unresolved paradox. Front Immunol 3: 199.

37. Dam TK, Brewer CF (2009) Lectins as pattern recognition molecules: The effects of epitope density in innate immunity. Glycobiol 20: 270-279.

38. Paszek MJ, Boettiger D, Weaver VM, Hammer DA (2009) Integrin clustering is driven by mechanical resistance from the glycocalyx and the substrate. PLoS Comput Biol 5: e1000604.

39. Chignalia AZ, Yetimakman F, Christiaans SC, Unal S, Bayrakci B, et al. (2016) The glycocalyx and trauma: A review. Shock 45: 338.

40. Preston S, Dunphy J, Beddoe T, Meeusen E, Young A, et al. (2015) Evaluation of the role of galectins in parasite immunity. In: Sean R. Stowell, Richard D. Cummings (eds.) Galectins: Methods and Protocols. Springer New York, USA pp: 371-395.

41. Lee Y-C (2011) In: Wu AM (eds) The molecular immunology of complex carbohydrates-3. Springer Science \& Business Media, Berlin, Germany.

42. Van Breedam W, Pöhlmann S, Favoreel HW, de Groot RJ, Nauwynck HJ (2014) Bitter-sweet symphony: Glycan-lectin interactions in virus biology. FEMS Microbiol Rev 38: 598-632.

43. Yan H, Kamiya T, Suabjakyong P, Tsuji NM (2015) Targeting C-type lectin receptors for cancer immunity. Front Immunol 6: 408.

44. O'Sullivan JA, Carroll DJ, Bochner BS (2017) Glycobiology of eosinophilic inflammation: Contributions of siglecs, glycans, and other glycan-binding proteins. Front Med 4: 116.

45. Yau T, Dan X, Ng CCW, Ng TB (2015) Lectins with potential for anticancer therapy. Molecules 20: 3791-3810.

46. Anderson K, Evers D, Rice KG (2008) Structure and function of mammalian carbohydrate-lectin interactions. In: Fraser-Reid BO, Tatsuta K, Thiem J (eds.) Glycoscience. Springer Berlin, Berlin, Germany pp: 2445-2482.

47. Plato A, Hardison SE, Brown GD (2015) Pattern recognition receptors in antifungal immunity. Semin Immunopathol 37: 97-106.

48. Kigerl KA, De Rivero Vaccari JP, Dietrich WD, Popovich PG, Keane RW (2014) Pattern recognition receptors and central nervous system repair. Experiment Neurol 258: 5-16.

49. Brubaker SW, Bonham KS, Zanoni I, Kagan JC (2015) Innate immune pattern recognition: A cell biological perspective. Ann Rev Immunol 33: 257-290.

50. Geijtenbeek TBH, Gringhuis SI (2016) C-type lectin receptors in the control of T helper cell differentiation. Nat Rev Immunol 16: 433.

51. Mollinedo F, Gajate C (2015) Lipid rafts as major platforms for signaling regulation in cancer. Adv Biol Regul 57: 130-146.

52. Levental I, Veatch S (2016) The continuing mystery of lipid rafts. J Mol Biol 428: 4749-4764.

53. Nagatsuka Y, Hara-Yokoyama M, Kasama T, Takekoshi M, Maeda F, et al (2003) Carbohydrate-dependent signaling from the phosphatidylglucoside-based microdomain induces granulocytic differentiation of HL60 cells. Proc Natl Acad Sci USA 100: 7454-7459. 
Page 7 of 9

54. Sezgin E, Levental I, Mayor S, Eggeling C (2017) The mystery of membrane organization: Composition, regulation and roles of lipid rafts. Nat Rev Mol Cell Biol 18: 361.

55. Sonnino S, Aureli M, Loberto N, Chigorno V, Prinetti A (2010) Fine tuning of cell functions through remodeling of glycosphingolipids by plasma membrane-associated glycohydrolases. FEBS lett 584: 1914-1922.

56. Nakayama H, Nagafuku M, Suzuki A, Iwabuchi K, Inokuchi JI (2018) The regulatory roles of glycosphingolipid-enriched lipid rafts in immune systems. FEBS Lett 592: 3921-3942.

57. Simons K, Toomre D (2000) Lipid rafts and signal transduction. Nat Rev Mol Cell Biol 1: 31 .

58. Lingwood D, Simons K (2010) Lipid rafts as a membrane-organizing principle. Science 327: 46-50.

59. Sangabathuni S, Murthy RV, Chaudhary PM, Subramani B, Toraskar S, et al. (2017) Mapping the glyco-gold nanoparticles of different shapes toxicity, biodistribution and sequestration in Adult Zebrafish. Scientific Rep 7: 4239.

60. Head BP, Patel HH, Insel PA (2014) Interaction of membrane/lipid rafts with the cytoskeleton: Impact on signaling and function: Membrane/lipid rafts, mediators of cytoskeletal arrangement and cell signaling. Biochim Biophys Acta 1838: 532-545.

61. Hakomori SI (2008) Structure and function of glycosphingolipids and sphingolipids: Recollections and future trends. Biochim Biophys Acta 1780: 325-346.

62. Munro S (2003) Lipid rafts: Elusive or illusive?. Cell 115: 377-388.

63. Jordan S, Rodgers W (2003) T cell glycolipid-enriched membrane domains are constitutively assembled as membrane patches that translocate to immune synapses. The J Immunol 171: 78-87.

64. Rabinovich GA, Toscano MA, Jackson SS, Vasta GR (2007) Functions of cell surface galectin-glycoprotein lattices. Curr Opin Struct Biol 17: 513-520.

65. Nabi IR, Shankar J, Dennis JW (2015) The galectin lattice at a glance. J Cell Sci 128: 2213-2219.

66. Justinich CJ, Seidman EG, Roy CC (2018) Elemental diet in food hypersensitivity. In: Bounous $\mathrm{G}$ (eds.) Uses of elemental diets in clinical situations (1st edn.) Taylor \& Francis, New York, USA pp: 301-315.

67. Xiao N, Liu F, Zhou G, Sun M, Ai F, et al. (2018) Food-specific IgGs are highly increased in the sera of patients with inflammatory bowel disease and are clinically relevant to the pathogenesis. Intern Med pp: 9377-9317.

68. Aalberse RC, Crameri R (2011) IgE-binding epitopes: A reappraisal. Allergy 66: 1261-1274.

69. Van Ree R, Cabanes-Macheteau M, Akkerdaas J, Milazzo JP, LoutelierBourhis C, et al. (2000) $\beta(1,2)$-xylose and $\alpha(1,3)$-fucose residues have a strong contribution in IgE binding to plant glycoallergens. J Biol Chem 275: 11451-11458.

70. Soh JY, Huang CH, Lee BW (2015) Carbohydrates as food allergens. Asia Pac Allergy 5: 17-24.

71. Wilson IBH, Altmann F (1998) Structural analysis of N-glycans from allergenic grass, ragweed and tree pollens: Core $\alpha 1$, 3-linked fucose and xylose present in all pollens examined. Glycoconj J 15: 1055-1070.

72. Wilson IBH, Zeleny R, Kolarich D, Staudacher E, Stroop CJM, et al (2001) Analysis of Asn-linked glycans from vegetable foodstuffs: Widespread occurrence of Lewis a, core $\alpha 1$, 3-linked fucose and xylose substitutions. Glycobiology 11: 261-274.

73. Mari A, Iacovacci P, Afferni C, Barletta B, Tinghino R, et al. (1999) Specific IgE to cross-reactive carbohydrate determinants strongly affect the in vitro diagnosis of allergic diseases. J Allergy Clin Immunol 103: 1005-1011.

74. Perez-Riverol A, Miehe M, Jabs F, Seismman H, Fernandes LGR, et al (2018) Venoms of neotropical wasps lack cross-reactive carbohydrate determinants enabling reliable protein-based specific IgE determination. J Allergy Clin Immunol 141: 1917-1919.

75. Hemmer W, Altmann F, Holzweber F, Gruber C, Wantke F, et al. (2018) Immuno-CAP cellulose displays cross-reactive carbohydrate determinant
(CCD) epitopes and can cause false-positive test results in patients with high anti-CCD IgE antibody levels. J Allergy Clin Immunol 141: 372-381.

76. Le Parc A, Lee H, Chen K, Barile D (2014) Rapid quantification of functional carbohydrates in food products. Food Sci Nutr 5: 71.

77. Batanero E, Crespo JF, Monsalve RI, Martín-Esteban M, Villalba M, et al. (1999) IgE-binding and histamine-release capabilities of the main carbohydrate component isolated from the major allergen of olive tree pollen. J Allergy Clin Immunol 103: 147-153.

78. Petersen A, Vieths S, Aulepp H, Schlaak M, Becker WM (1996) Ubiquitous structures responsible for IgE cross-reactivity between tomato fruit and grass pollen allergens. J Allergy Clin Immunol 98: 805-815.

79. Echeverria B, Serna S, Achilli S, Vivès C, Pham J, et al. (2018) Chemoenzymatic synthesis of n-glycan positional isomers and evidence for branch selective binding by monoclonal antibodies and human C-type lectin receptors. ACS Chem Biol 13: 2269-2279.

80. Ludwig DS, Hu FB, Tappy L, Brand-Miller J (2018) Dietary carbohydrates: Role of quality and quantity in chronic disease. BMJ 361: $\mathrm{k} 2340$.

81. Abuajah CI, Ogbonna AC, Osuji CM (2015) Functional components and medicinal properties of food: A review. J Food Sci Technol 52: 2522-2529.

82. Mehta N, Ahlawat SS, Sharma DP, Dabur RS (2015) Novel trends in development of dietary fiber rich meat products-a critical review. J Food Sci Techno 52: 633-647.

83. Koh A, De Vadder F, Kovatcheva-Datchary P, Bäckhed F (2016) From dietary fiber to host physiology: Short-chain fatty acids as key bacterial metabolites. Cell 165: 1332-1345.

84. Holscher HD (2017) Dietary fiber and prebiotics and the gastrointestinal microbiota. Gut Microbes 8: 172-184.

85. Míguez B, Gómez B, Gullón P, Gullón B, Alonso JL (2016) Pectic ccoligosaharides and other emerging prebiotics. In: Rao V, Rao LG (eds.) Probiotics and Prebiotics in Human Nutrition and Health InTech Open, London, UK, p: 1351.

86. Morozov V, Hanisch FG, Wegner M, Schroten H (2018) Pandemic GII. 4 sydney and epidemic GII. 17 kawasaki308 noroviruses display distinct specificities for histo-blood group antigens leading to different transmission vector dynamics in pacific oysters. Front Microbiol 9: 2826.

87. Shirato H (2015) Norovirus and histo-blood group antigens. Jpn J Infect Dis 64: 731-735.

88. Li D, Baert L, Xia M, Zhong W, Jiang X, et al. (2012) Effects of a variety of food extracts and juices on the specific binding ability of norovirus GII. 4 P particles. J Food Prot 75: 1350-1354.

89. Hirneisen KA, Kniel KE (2013) Norovirus attachment: Implications for food safety. Food Prot Trends 33: 290-299.

90. Gao X, Esseili MA, Lu Z, Saif LJ, Wang Q (2016) Recognizing HBGA-like carbohydrates in lettuce by human GII. 4 norovirus. Appl Environ Microbiol 82: 2966-2974.

91. Franchini M, Bonfanti C (2015) Evolutionary aspects of ABO blood group in humans. Clinica Chimica Acta 444: 66-71.

92. Lausten MB, Rasmussen S, Gazerani P (2018) Association between the ABO blood types and post-operative pain. Eur Neurol Rev 13: 38-43.

93. Wolpin BM, Chan AT, Hartge P, Chanock SJ, Kraft P, et al. (2009) ABO blood group and the risk of pancreatic cancer. J Natl Cancer Inst 101: 424-431.

94. Monedero V, Buesa J, Rodríguez-Díaz J (2018) The interactions between host glycobiology, bacterial microbiota, and viruses in the gut. Viruses 10: 96.

95. Carmona-Vicente $\mathrm{N}$, Allen DJ, Rodríguez-Díaz J, Iturriza-Gómara $\mathrm{M}$, Buesa J (2016) Antibodies against Lewis antigens inhibit the binding of human norovirus GII. 4 virus-like particles to saliva but not to intestinal Caco-2 cells. Virol J 13: 82.

96. Le Pendu J, Marionneau S, Cailleau-Thomas A, Rocher J, Le MoullacVaidye B, et al. (2001) ABH and Lewis histo-blood group antigens in cancer. Apmis 109: 9-26.

97. Reid ME, Lomas-Francis C, Olsson ML (2012) The blood group antigen factsbook. Academic Press, Massachusetts, US. 
98. Marionneau S, Ruvoën N, Le Moullac-Vaidye B, Clement M, CailleauThomas A, et al. (2002) Norwalk virus binds to histo-blood group antigens present on gastroduodenal epithelial cells of secretor individuals. Gastroenterology 122: 1967-1977.

99. Huang P, Farkas T, Zhong W, Tan M, Thornton S, et al. (2005) Norovirus and histo-blood group antigens: demonstration of a wide spectrum of strain specificities and classification of two major binding groups among multiple binding patterns. J Virol 79: 6714-6722.

100. Marionneau S, Cailleau-Thomas A, Rocher J, Le Moullac-Vaidye B, Ruvoën N, et al. (2001) ABH and Lewis histo-blood group antigens, a model for the meaning of oligosaccharide diversity in the face of a changing world. Biochimie 83: 565-573.

101. Fenderson BA, Zehavi U, Hakomori SI (1984) A multivalent lacto-Nfucopentaose III-lysyllysine conjugate decompacts preimplantation mouse embryos, while the free oligosaccharide is ineffective. J Exp Med 160: 1591-1596.

102. Newburg DS, He Y (2015) Neonatal gut microbiota and human milk glycans cooperate to attenuate infection and inflammation. Clin Obstet Gynecol 58: 814-826.

103. Ali ES, Rajapaksha H, Carr JM, Petrovsky N (2016) Norovirus drug candidates that inhibit viral capsid attachment to human histo-blood group antigens. Antiviral Res 133: 14-22.

104. Cohen M, Hurtado-Ziola N, Varki A (2009) ABO blood group glycans modulate sialic acid recognition on erythrocytes. Blood 114: 3668-3676.

105. Varki A (1994) Selectin ligands. Proc Natl Acad Sci USA 91: 7390-7397.

106. Cohen M, Varki A (2014) Modulation of glycan recognition by clustered saccharide patches. Int Rev Cell Mol Biol 308: 75-125.

107. Cohen M (2015) Notable aspects of glycan-protein interactions. Biomolecules 5: 2056-2072.

108. Ambrosi M, Cameron NR, Davis BG (2005) Lectins: Tools for the molecular understanding of the glycocode. Org Biomol Chem 3: 1593-1608.

109. Godula K (2018) Following sugar patterns in search of galectin function. Proc Natl Acad Sci 115: 2548-2550.

110. Lundquist JJ, Toone EJ (2002) The cluster glycoside effect. Chem Rev 102: 555-578.

111. Hirabayashi J, Hashidate T, Arata Y, Nishi N, Nakamura T, et al. (2002) Oligosaccharide specificity of galectins: A search by frontal affinity chromatography. Biochim Biophys Acta 1572: 232-254.

112. He S, Simpson BK, Sun H, Ngadi MO, Ma Y, et al. (2018) Phaseolus vulgaris lectins: A systematic review of characteristics and health implications. Crit Rev Food Sci Nutr 58: 70-83.

113. Belitz H, Grosch W, Schieberle P (2009) Food chemistry 4th revised and extendended edition. Germany: Springer-Verlag Berlin Heidelberg Cooking Properties of Raw and Baked patties from Goat Meat. J Food Eng 53: 377-385.

114. Gupta GS (2012) Animal lectins: form, function and clinical applications. Springer Science \& Business Media, Berlin, Germany.

115. Anthony H, Jia-Hau LIU (2003) Effect of polyvalencies of glycotopes on the binding of a lectin from the edible mushroom, Agaricus bisporus. Biochem J 371: 311-320.

116. Kletter D, Cao Z, Bern M, Haab B (2013) Determining lectin specificity from glycan array data using motif segregation and GlycoSearch software. Curr Protoc Chem Biol 5: 157-169.

117. Singh T, Chatterjee U, Wu JH, Chatterjee BP, Wu AM (2004) Carbohydrate recognition factors of a $\mathrm{T} \alpha(\mathrm{Gal} \beta 1 \rightarrow 3 \mathrm{GalNAc} \alpha 1 \rightarrow \mathrm{Ser} / \mathrm{Thr})$ and $\mathrm{Tn}$ (GalNAcal $\rightarrow$ Ser/Thr) specific lectin isolated from the seeds of Artocarpus lakoocha. Glycobiology 15: 67-78.

118. Hamid R, Masood A (2009) Dietary lectins as disease causing toxicants Pak J Nutr 8: 293-303.

119. Roy F, Boye JI, Simpson BK (2010) Bioactive proteins and peptides in pulse crops: Pea, chickpea and lentil. Food Res Int 43: 432-442.

120. Mbae KM, Umesha S, Manukumar HM (2018) Therapeutic properties of lectins in herbal supplements. Phytochem Rev 17: 627-643.

121. Vasta GR (2009) Roles of galectins in infection. Nat Rev Microbiol 7: 424.
122. Stowell SR, Arthur CM, Dias-Baruffi M, Rodrigues LC, Gourdine JP, et al. (2010) Innate immune lectins kill bacteria expressing blood group antigen. Nat Med 16: 295-301.

123. Bilotta AJ, Ma C, Huang X, Yang W, Chen L, et al. (2018) Microbiota metabolites SCFA promote intestinal epithelial repair and wound healing through promoting epithelial cell production of milk fat globule-EGF factor 8. Am Assoc Immnol 53: 17.

124. Bishehsari F, Engen PA, Preite NZ, Tuncil YE, Naqib A, et al. (2018) Dietary fiber treatment corrects the composition of gut microbiota promotes SCFA production, and suppresses colon carcinogenesis. Genes 9: 102.

125. Durbin SV, Wright WS, Gildersleeve JC (2018) Development of a multiplex glycan microarray assay and comparative analysis of human serum anti-glycan IgA, IgG, and IgM repertoires. ACS Omega 3: 16882-16891.

126. Newburg DS (2009) Neonatal protection by an innate immune system of human milk consisting of oligosaccharides and glycans. J Anim Sci 87: 26-34.

127. Hall MK, Weidner DA, Zhu Y, Dayal S, Whitman AA, et al. (2016) Predominant expression of hybrid N-glycans has distinct cellular roles relative to complex and oligomannose N-glycans. Int J Mol Sci 17: 925.

128. Cohen M, Varki A (2010) The sialome-far more than the sum of its parts. Omics 14: 455-464.

129. Edgren G, Hjalgrim H, Rostgaard K, Norda R, Wikman A, et al. (2010) Risk of gastric cancer and peptic ulcers in relation to ABO blood type: A cohort study. Am J Epidemiol 172: 1280-1285.

130. Lübbers J, Rodriguez E, Van Kooyk Y (2018) Modulation of immune tolerance via Siglec-sialic acid interactions. Front Immunol 9: 2807.

131. Almand EA, Moore MD, Jaykus LA (2017) Norovirus binding to ligands beyond histo-blood group antigens. Front Microbiol 8: 2549.

132. Hakomori SI, Igarashi Y (1995) Functional role of glycosphingolipids in cell recognition and signaling. J Biochem 118: 1091-1103.

133. Sharon N, Lis H (2004) History of lectins: From hemagglutinins to biological recognition molecules. Glycobiology 14: 53R-62R.

134. Matsuura K, Kitakouji H, Sawada N, Ishida H, Kiso M, et al. (2000) A quantitative estimation of carbohydrate-carbohydrate interaction using clustered oligosaccharides of glycolipid monolayers and of artificial glycoconjugate polymers by surface plasmon resonance. J Am Chem Soc 122: 7406-7407.

135. Rinaldi S, Brennan KM, Goodyear CS, O'Leary C, Schiavo G, et al. (2009) Analysis of lectin binding to glycolipid complexes using combinatorial glycoarrays. Glycobiology 19: 789-796.

136. Hasan S, Osickova A, Bumba L, Novák P, Sebo P, et al. (2015) Interaction of Bordetella adenylate cyclase toxin with complement receptor 3 involves multivalent glycan binding. FEBS Lett 589: 374-379.

137. Purohit S, Li T, Guan W, Song X, Song J, et al. (2018) Multiplex glycan bead array for high throughput and high content analyses of glycan binding proteins. Nat Commun 9: 258.

138. Giovannone N, Smith LK, Treanor B, Dimitroff CJ (2018) Galectinglycan interactions as regulators of B cell immunity. Front Immunol 9: 2839.

139. Eggens I, Fenderson B, Toyokuni T, Dean B, Stroud M, et al. (1989) Specific interaction between Lex and Lex determinants: A possible basis for cell recognition in preimplantation embryos and in embryonal carcinoma cells. J Biol Chem 264: 9476-9484.

140. Becker DJ, Lowe JB (2003) Fucose: Biosynthesis and biological function in mammals. Glycobiology 13: 41R-53R.

141. Yu S, Kojima N, Hakomori SI, Kudo S, Inoue S, et al. (2002) Binding of rainbow trout sperm to egg is mediated by strong carbohydrate-tocarbohydrate interaction between (KDN) GM3 (deaminated neuraminyl ganglioside) and Gg3-like epitope. Proc Natl Acad Sci USA 99: 2854-2859.

142. Kawashima N, Yoon SJ, Itoh K, Nakayama KI (2009) Tyrosine kinase activity of epidermal growth factor receptor is regulated by GM3 binding 
through carbohydrate to carbohydrate interactions. J Biol Chem 284 6147-6155.

143. Garcia-Manyes S, Bucior I, Ros R, Anselmetti D, Sanz F, et al. (2006) Proteoglycan mechanics studied by single-molecule force spectroscopy of allotypic cell adhesion glycans. J Biol Chem 281: 5992-5999.

144. Vilanova E, Santos GRC, Aquino RS, Valle-Delgado JJ, Anselmetti D, et al. (2016) Carbohydrate-carbohydrate interactions mediated by sulfate esters and calcium provide the cell adhesion required for the emergence of early metazoans. J Biol Chem 291: 9425-9437.

145. Misevic GN, Burger MM (1990) The species-specific cell-binding site of the aggregation factor from the sponge Microciona prolifera is a highly repetitive novel glycan containing glucuronic acid, fucose, and mannose. J Biol Chem 265: 20577-20584.

146. Spillmann D, Thomas-Oates JE, Van-Kuik JA, Vliegenthart JFG, Misevic G, et al. (1995) Characterization of a novel sulfated carbohydrate unit implicated in the carbohydrate-carbohydrate-mediated cell aggregation of the marine sponge Microciona prolifera. J Biol Chem 270: 5089-5097.

147. Haseley SR, Vermeer HJ, Kamerling JP, Vliegenthart JFG (2001)Carbohydrate self-recognition mediates marine sponge cellular adhesion. Proc Natl Acad Sci USA 98: 9419-9424.

148. Winklbauer R (2015) Cell adhesion strength from cortical tension-an integration of concepts. J Cell Sci 128: 3687-3693.

149. Day CJ, Tran EN, Semchenko EA, Tram G, Hartley-Tassell LE, et al. (2015) Glycan: Glycan interactions: High affinity biomolecular interactions that can mediate binding of pathogenic bacteria to host cells. Proc Natl Acad Sci USA 112: E7266-E7275.

150. Zhang X, Kiechle FL (2004) Glycosphingolipids in health and disease. Ann Clin Lab Sci 34: 3-13.

151. Sherwin E, Dinan TG, Cryan JF (2018) Recent developments in understanding the role of the gut microbiota in brain health and disease. Ann NY Acad Sci 1420: 5-25.

152. Anand S, Mande SS (2018) Diet, microbiota and gut-lung connection. Front in Microbiol 9: 2147.

153. Fellows R, Denizot J, Stellato C, Cuomo A, Jain P, et al. (2018) Microbiota derived short chain fatty acids promote histone crotonylation in the colon through histone deacetylases. Nat Commun 9: 105.

154. Formosa-Dague C, Castelain M, Yken HM, Dunker K (2018) The role of glycans in bacterial adhesion to mucosal surfaces: How can singlemolecule techniques advance our understanding?. Microorganisms 6: 39 .

155. Berger A, Mainou B (2018) Interactions between enteric bacteria and eukaryotic viruses impact the outcome of infection. Viruses 10: 19.

156. Luis AS, Briggs J, Zhang X, Farnell B, Ndeh D, et al. (2018) Dietary pectic glycans are degraded by coordinated enzyme pathways in human colonic bacteroides. Nat Microbiol 3: 210-219.

157. Rodríguez JM, Murphy K, Stanton C, Ross RP, Kober OI, et al. (2015) The composition of the gut microbiota throughout life, with an emphasis on early life. Microb Ecol Health Dis 26: 26050.

158. Makki K, Deehan EC, Walter J, Backhed F (2018) The impact of dietary fiber on gut microbiota in host health and disease. Cell Host Microbe 23: 705-715.

159. Desselberger U (2018) The mammalian intestinal microbiome: Composition, interaction with the immune system, significance for vaccine efficacy, and potential for disease therapy. Pathogens 7: 57.
160. Huflejt ME, Vuskovic M, Vasiliu D, Xu H, Obukhova P, et al. (2009) Anticarbohydrate antibodies of normal sera: Findings, surprises and challenges. Mol Immunol 46: 3037-3049.

161. Amoah AS, Brempong EK, Obeng BB, Versteeg SA, Larbi IA, et al. (2018) Identification of dominant anti-glycan IgE responses in school children by glycan microarray. J Allergy Clin Immunol 141: 1130-1133.

162. Diccianni MB, Mielke J, Williams R, Messer K, Ozkaynak F, et al. (2018) Natural antibodies to non-human glycans Neu5Gc and alpha-gal correlate with outcome of high-risk neuroblastoma patients treated with dinutuximab on COG ANBL0032 and ANBL0931. Cancer Res 78: LB-300.

163. Heesterbeek DAC, Angelier ML, Harrison RA, Rooijakkers SHM (2018) Complement and bacterial infections: From molecular mechanisms to therapeutic applications. J Innate Immun 10: 455-464.

164. Troldborg A, Thiel S, Trendelenburg M, Friebus-Kardash J, Nehring J, et al. (2018) The lectin pathway of complement activation in patients with systemic lupus erythematosus. J Rheumatol 45: 1136-1144.

165. De-Blasio D, Fumagalli S, Orsini F, Neglia L, Perego C, et al. (2018) Human brain trauma severity is associated with lectin complement pathway activation. J Cereb Blood Flow Metab 9: 271678X18758881.

166. Howard M, Farrar CA, Sacks SH (2018) Structural and functional diversity of collectins and ficolins and their relationship to disease. Semin Immunopathol 40: 75-85.

167. Picca A, Lezza AMS, Leeuwenburgh C, Pesce V, Calvani R, et al. (2018) Circulating mitochondrial DNA at the crossroads of mitochondrial dysfunction and inflammation during aging and muscle wasting disorders. Rejuvenation Res 21: 350-359.

168. Fischer R, Schillberg S (2004) Molecular farming: Plant-made pharmaceuticals and technical proteins. Ann Bot 96: 343.

169. Sanada F, Taniyama Y, Muratsu J, Otsu R, Shimizu H, et al. (2018) Source of chronic inflammation in aging. Front Cardiovasc Med 5: 12.

170. Guzik TJ, Cosentino F (2018) Epigenetics and immunometabolism in diabetes and aging. Antioxid Redox Signal 29: 257-274.

171. D'Adamo PJ, Whitney C (1996) Eat right 4 your type. GP Putnam's Sons, New York, USA.

172. Moen T (2001) "Blood type diet" science or fantasy? Tidsskrift for den Norske laegeforening: Tidsskrift for praktisk medicin, ny raekke 121: 355-358.

173. Cusack L, De Buck E, Compernolle V, Vandekerckhove P (2013) Blood type diets lack supporting evidence: A systematic review. Am J Clin Nutr 98: 99-104.

174. Wu AM, Singh T, Liu JH, Krzeminski M, Russwurm R, et al. (2006) Activity-structure correlations in divergent lectin evolution: Fine specificity of chicken galectin CG-14 and computational analysis of flexible ligand docking for CG-14 and the closely related CG-16. Glycobiology 17: 165-184.

175. Barboza M, Wong M, Luke J, Cheng Z, Xu G, et al. (2018) System metaglycomes: Mapping dynamic cell surface $\mathrm{N}$-glycome, O-glycome and Glycolipidome by mass spectrometry. FASEB J 32: 673-11.

176. Sandilya VB (2018) Unraveling the isomeric heterogeneity of glycans: Ion mobility separations in structures for lossless ion manipulations. Chem Commun 54: 11701-11704. 